\title{
Rb knockdown accelerates bladder cancer progression through E2F3 activation
}

\author{
JIANG-PING WANG* , YONG JIAO* , CHENG-YUAN WANG, ZHI-BIN XU and BO ZHANG \\ Department of Urology, Tangdu Hospital, The Fourth Military Medical University, Xi'an, Shaanxi 710038, P.R. China
}

Received October 6, 2016; Accepted November 21, 2016

DOI: 10.3892/ijo.2016.3791

\begin{abstract}
Bladder cancer is one of the most common cancers diagnosed in the world and leads to significant mortality and morbidity among affected patients. The retinoblastoma $(\mathrm{Rb})$ protein is a main tumor suppressor, controlling cellular responses to potentially oncogenic stimulation. E2F3 was invariably disrupted in different human cancers for its central role in the control of cellular proliferation. Here, we investigated how $\mathrm{Rb}$ is integrated to control bladder cancer progression through $\mathrm{E} 2 \mathrm{~F} 3$ and $\mathrm{p} 53$ regulation. The results exhibit that $\mathrm{Rb}$ expression is lower in patients with bladder tumor, while E2F3 level is high. Rb knockdown enhanced bladder tumor cell proliferation and migration, aggravated with p53 silence. Interestingly, Rb silence results in E2F3, Myc and mTOR signaling pathway activation, contributing to bladder cancer cell proliferation and apoptosis suppression mainly through caspase-3 inhibition in vitro and in vivo. Immunohistochemical analysis revealed that $\mathrm{Rb}$ is highly expressed in normal bladder cells, but was repressed in tumor tissues of the bladder completely, suggesting a possible role of $\mathrm{Rb}$ as a tumor suppressor.
\end{abstract}

\section{Introduction}

Bladder cancer is one of the most common urological malignancy across the world (1). Approximately, $70 \%$ of tumors or cancers display indications for non-muscle-invasive bladder cancer (NMIBC) during the initial diagnosis with mutable danger of recurrence and development to invasive disease, hence needing long-term surveillance $(2,3)$. As the goldstandard therapy, intravesical IVES Bacillus-Calmette-Guerin BCG immunotherapy after the lesion transurethral resection has been used for $\sim 40$ years (4). However, this therapy was limited among patients during the tumor recurrence and

Correspondence to: Dr B. Zhang, Department of Urology, Tangdu Hospital, The Fourth Military Medical University, Xi'an, Shaanxi 710038, P.R. China

E-mail: zhangbo@fmmu.edu.cn

*Contributed equally

Key words: bladder cancer, $\mathrm{Rb}, \mathrm{E} 2 \mathrm{~F} 3$ and $\mathrm{p} 53$, proliferation, apoptosis progression. Therefore, finding an effective target for treating bladder cancer is still necessary.

The retinoblastoma $(\mathrm{Rb})$ protein is a main tumor suppressor, potentially controlling cellular processes or responses to oncogenic stimuli, such as DNA damage, repeated rapid cell division, as well as inappropriate mitogenic signals $(5,6)$. The significance of $\mathrm{Rb}$ protein in tumor development was initially showed by the results that an RB allele was unchangeably deleted in retinoblastoma (7). $\mathrm{Rb}$ modulates normal cell cycle and responses to stress. The progression of cell cycle is controlled by various cyclin-dependent kinases (CDKs), which could bind to their respective cyclins and promote phosphorylation (8). The activated cyclins and their CDKs subsequently phosphorylate $\mathrm{Rb}$, which is significant for E2Fs activity modulation (9). Rb phosphorylation could disrupt E2F complex formation, resulting in diverse transcription factors dysfunction and some targeting genes to enhance entry into $\mathrm{S}$ phase, which is vital for cell proliferation and influences tumor development and progression (10). Additionally, E2F3 and Myc are important transcription factors, which control cellular proliferation. E2F3, as a major transcriptional activator, could be suppressed combined with $\mathrm{Rb}$.

The tumor suppressor p53 regulates several cellular stress responses, such as apoptosis, cell cycle arrest, and genomic stability, through induction of the various transcription of target genes $(11,12)$. Responding to different genotoxic stresses, p53 could be activated via interactivation with various kinases, which include negative cell cycle-related genes and anti- or proapoptotic genes of Bcl-2 and Bax (13). Previous reports have suggested that $\mathrm{Rb}$ and $\mathrm{p} 53$ deletion in cells led to small cell lung cancer $(14,15)$. Also, tumors with $\mathrm{Rb}$ and p53 deletion accelerated lung cancer progression through Myc promotion (16).

Despite significant function between E2F and Myc for the control of cell cycle modulation regulated by $\mathrm{Rb}$ and $\mathrm{p} 53$, the specific molecular mechanisms linking these critical transcriptional programs are poorly understood in bladder cancer progression. We estimated Rb, E2F3 and p53 in cells of the bladder cancer in order to better understand and define how these factors regulate the cell cycle and apoptosis in vitro and in vivo of bladder cancer.

\section{Materials and methods}

Sample collection. A total of 26 bladder cancer samples were obtained from patients undergoing cystectomy at 
Tangdu Hospital, The Fourth Military Medical University (Shaanxi, China), between 2012 and 2014 for further verification. Follow-up data were available for each patient. Tissue samples from primary tumors were collected and prepared for RT-qPCR, immunohistochemical (IHC) staining and western blot analysis. The fresh-frozen tissue samples from 26 bladder patients and matched normal bladder tissues were collected and snap-frozen in liquid nitrogen immediately within $10 \mathrm{~min}$ after collection. The tissue sample collection and experimental procedures were conducted with the approval of the Institutional Review Board of Tangdu Hospital.

Cell culture and treatment. The bladder cancer cells of BIU87, as well as human normal bladder epithelial cell of T24 were obtained from American Type Culture Collection (ATCC, Rockville, MD, USA). They were cultured at the permissive temperature $\left(37^{\circ} \mathrm{C}\right)$ in DMEM medium (Gibco BRL, Grand Island, NY, USA) containing $10 \%$ fetal bovine serum (FBS) and supplemented with $1 \%$ penicillin-streptomycin-neomycin provided by Gibco BRL Life Technologies with a humidified incubator in $5 \% \mathrm{CO}_{2}$ atmosphere. Additional introduction of $\mathrm{Rb}$ or a control vector into BIU87 cells were described previously (17).

Colony formation assay. One hundred bladder cancer cells of BIU87 after the vector control or siRb treatment per well in 60-mm plates were cultured in 10\% FBS DMEM for $24 \mathrm{~h}$. After another 7 days of incubation, the cell colonies were washed twice with PBS, fixed with $4 \%$ paraformaldehyde for $15 \mathrm{~min}$ and then stained by Giemsa for $30 \mathrm{~min}$. Clones with $>50$ cells were evaluated. Clone forming efficiency for cells was calculated based on colonies/number of inoculated cells $\mathrm{x} 100 \%$.

Wound-healing assay. Wound-healing assays were carried out using migration culture dish inserts. Bladder cancer cells of BIU87 after the vector control or siRb treatment were seeded in the chambers of the culture dish insert and transfected. Twenty-four hours after transfection, the insert was removed and fresh culture medium was added to start the migration process. Images were acquired after 0 and $24 \mathrm{~h}$ using a Zeiss Axiovert 24 light microscope and an Axiocam MRc camera.

Transwell migration assay. Bladder cancer cells after treatment were seeded into the upper chamber of a Transwell insert pre-coated with $5 \mu \mathrm{g} / \mathrm{ml}$ fibronectin for migration or a $\mathrm{BD}^{\mathrm{TM}}$ Matrigel invasion chamber for invasion. Medium with $10 \%$ serum was put in the lower chamber to play as a chemoattractant, and cells were then incubated for $4 \mathrm{~h}$ of migration. Non-migratory cells were taken away from the upper chamber via scraping with a cotton bud. The cells on the lower insert surface were stained with Diff-Quick. Cells were evaluated as the number of cells observed in five different microscope fields of two independent inserts.

Terminal deoxynucleotidyl transferase-mediated dUTP nick end labeling (TUNEL) assays. Apoptosis assay of samples was also determined by TUNEL used an In Situ Cell Death Detection kit, Fluorescein (Roche Applied Science, South San Francisco, CA, USA) according to the manufacturer's protocol. The number of TUNEL-positive cells was counted under a fluorescence microscope. The percentages of apoptotic cells were calculated from the ratio of apoptotic cells to total cells counted. Tissue sections were counter-stained with hematoxylin. Sections were mounted and observed under light microscopy. The experiment was performed independently three times.

Antibody array detection. In total, $1 \times 10^{6}$ BIU87 cells expressing a control vector or siRNAs of $\mathrm{Rb}$ were seeded into 10 -cm culture dishes for $24 \mathrm{~h}$. Then the media were replaced with serum deprived media ( $0.1 \%$ fetal bovine serum), and the bladder cancer cells were cultured for another $48 \mathrm{~h}$. The supernatants of culture were acquired, centrifuged at $1,000 \mathrm{xg}$, and dialyzed with $1 \mathrm{X}$ phosphate-buffered saline with $\mathrm{pH} 8.0$ twice overnight at $4^{\circ} \mathrm{C}$. The samples were then labeled with biotin and then incubated with human L1000 Antibody arrays (RayBiotech, Norcross, GA, USA).

Western blot analysis. The bladder cancer cells and tumor tissue samples were homogenized into $10 \%$ (wt/vol) hypotonic buffer (25 mM Tris-HCl, pH 8.0, $1 \mathrm{mM}$ EDTA, $5 \mu \mathrm{g} / \mathrm{ml}$ leupeptin, $1 \mathrm{mM}$ Pefabloc SC, $50 \mu \mathrm{g} / \mathrm{ml}$ aprotinin, $5 \mu \mathrm{g} / \mathrm{ml}$ soybean trypsin inhibitor, $4 \mathrm{mM}$ benzamidine) to yield a homogenate. Then the final supernatants were obtained by centrifugation at $12,000 \mathrm{rpm}$ for $20 \mathrm{~min}$. Protein concentration was determined by BCA protein assay kit (Thermo Fisher Scientific, USA) with bovine serum albumin as a standard. The total protein extract will be used for western blot analysis. Equal amounts of total protein of tissues were subjected to 10 or $12 \%$ SDS-PAGE followed by immunoblotting using the following primary polyclonal antibodies: rabbit anti-GAPDH (Cell Signaling Technology, USA), rabbit anti-Myc (Cell Signaling Technology), rabbit anti-PARP (Cell Signaling Technology), rabbit anti-E2F3 (Abcam, USA), rabbit anti-caspase-9 (Abcam), rabbit anti-caspase-3 (Abcam), mouse anti-Bcl-2 (Cell Signaling Technology), rabbit anti-P-Rb (Cell Signaling Technology), rabbit anti-Rb (Cell Signaling Technology), mouse anti-cyclin D1 (Abcam), mouse anti-cyclin A (Abcam), mouse anti-CDK4 (Abcam), and mouse anti-CDK2 (Abcam). Immunoreactive bands were visualized by ECL Immunoblot Detection system (Pierce Biotechnology, Inc., Rockford, IL, USA) and exposed to Kodak (Eastman Kodak Co., USA) $\mathrm{X}$-ray film. Each protein expression level was defined as grey value (Version 1.4.2b, Mac OS X, ImageJ, National Institutes of Health, USA) and standardized to housekeeping genes (GAPDH) and expressed as a fold of control.

Real-time RT-qPCR. Total RNA from bladder cancer cells and tumors were isolated using TRIzol (Invitrogen, Carlsbad, CA, USA) according to the manufacturer's instructions. The cDNA was synthesized using SuperScript II reverse transcriptase (Thermo Fisher Scientific). Quantitative PCR was performed with SYBR Green Real-Time PCR Master mix (Thermo Fisher Scientific). Finally, the quantitative expression data were collected and analyzed by a 7900 Real-time PCR system (Applied Biosystems, USA). Primers were designed to determine endogenous genes as follows and GAPDH was used as the endogenous control. eIF4E forward, 5'-CTG ATG TTG CTT GTC GCT TC-3'; reverse, 5'-GTG AGA GTT GCT GGC 
TTG AA-3'. eIF4G forward, 5'-CGA GGC TAC GCA TTT AGG AGA A-3'; reverse, 5'-GGG CTA TGA ACA GTC TCT TCT C-3'. Rb forward, 5'-AAC CCA GGA AGG AAT GGC T-3'; reverse, 5'-CTG CGT TCA GGT GAT TGA TG-3'. p53 forward, 5'-CTA CTG CCT GCT TTG CGG CGT-3'; reverse, 5'-GAA GCG GCG TAG GTG CTG AG-3'. E2F3 forward, 5'-CGC CAC CGC CAT CTT CTC CA-3'; reverse, 5'-GCA CAA GGC AGC CAG AAG GC-3'. mTOR forward, 5'-AGG ATC GCG CTT AGC ATA CTT G-3'; reverse, 5'-ATC TCT TCG ACC TCT GTT CTC G-3'. TSC-2 forward, 5'-CGT TCC TCA CGC TGG ACT CCT-3'; reverse, 5'-ACA GCG GAT AAC CTC CTG CTG TT-3'. SESN2 forward, 5'-CCA TTG AAG CCG AGG ATG TGG-3'; reverse, 5'-GTG GCC TCT GTT CAG CTA GGT-3'. GAPDH forward, 5'-CTA AGT CGA ACG CAG ACA GTC AG-3'; reverse, 5'-AAC ATA CCA TCC ACG ACA CGC TC-3'.

Flow cytometry for cell cycle analysis. The bladder cancer cells were fixed with $70 \%$ ethanol and washed with PBS with $1 \%$ horse serum, and cellular DNA was stained with $100 \mu \mathrm{g} / \mathrm{ml}$ propidium iodide. Cell cycle and forward scatter profiles were calculated through a Becton-Dickinson FACSCalibur, as determined by ModFit LT 2.0 from Verity Software House Inc.

Animals and treatment. The mouse experiments were conducted in the Animal Laboratory Center. BIU87 cells $\left(1 \times 10^{7}\right.$ cells) treated with the vector control and siRb were suspended in $100 \mu \mathrm{l}$ serum-free medium and injected subcutaneously into the left flank of 4- to 6-week old male BALB/c nu/nu nude mice. Tumor size was measured with digital caliper and calculated. Tumor volume were measured every seven days and at the end of $\sim 6$ weeks after treatment, mice were sacrificed. Tumors were excised, weighed, fixed in $10 \%$ neutral formalin, and embedded in paraffin for histological and western blot analysis.

Immunohistochemistry analysis. Human bladder or bladder cancer tissue samples and animal model bladder cancer tissue specimans were fixed in paraformaldehyde and embedded in paraffn. For hematoxylin and eosin staining (H\&E staining), the bladder tumor sections were incubated in a hematoxylin solution for $15 \mathrm{~min}$ and then counterstained with eosin for $5 \mathrm{~min}$. After $3 \mu \mathrm{m}$ thickness sectioning, paraffn-embedded bladder cancer tissues were performed for immunostaining with anti-pRb (Cell Signaling Technology), anti-E2F3 (Cell Signaling Technology), anti-P53 (Cell Signaling Technology), anti-Myc (Cell Signaling Technology), anti-Ki67 (Glostrup, Denmark), anti-cleaved caspase-3 (Cell Signaling Technology) and anti-mTOR (Abcam, UK) antibodies. All of the slides were finally observed with x200 magnification by microscopy.

Immunofluorescence assays. After induction by conditioned culture medium, the cells were fixed in $4 \%$ paraformaldehyde, permeabilized with $0.1 \%$ Triton $\mathrm{X}-100$ in PBS containing $0.5 \%$ BSA (PBS-BSA) for $30 \mathrm{~min}$. The cells were subsequently incubated with E2F3, Myc, mTOR, and p-AKT for $30 \mathrm{~min}$, followed by labeling with Alexa Fluor 488- and 594-conjugated rabbit anti-mouse or goat anti-rabbit $\operatorname{IgG}$ antibody. The cells were viewed under a fluorescent microscope.
Statistical analysis. Every experiment in our study was conducted at least three times. All data present the mean \pm SEM from three independent experiments. Student's t-test was used for statistical analysis.

\section{Results}

Patients with bladder cancer express low levels of $R b . \mathrm{Rb}$ has been well known to be of great importance during tumor progression and development, including liver cancer, breast cancer and lung cancer (18). However, whether Rb was involved in bladder cancer was far from clear. In this regard, we first investigated how $\mathrm{Rb}$ changed in different tissue samples. In Fig. 1A, we found that $\mathrm{Rb}$ expressed highly in normal bladder tissue samples from patients compared to the tumor tissue samples from patients with bladder tumor. Consistently, p53, as significant tumor suppressor, was discovered with lower levels in the tumor tissue segments compared to the normal tissue samples (Fig. 1B) (19). In contrast, mTOR was expressed highly in tumor samples, which has been reported to be linked with cancer progression and growth (Fig. 1C) (20). In agreement with mTOR, E2F3, which was a vital down-streaming signal of $\mathrm{Rb}$ and was associated with tumor development, was found to be upregulated in tumor tissue samples in comparison to the normal ones (Fig. 1D) (21). Also, western blot analysis indicated that the phosphorylated $\mathrm{Rb}$, the inactivated form, was increased in tumor tissue samples, which was contrary to the $\mathrm{Rb}$ levels in normal and tumor samples (Fig. 1E). Furthermore, immunohistochemical analysis indicated that $\mathrm{p}-\mathrm{Rb}$ and $\mathrm{E} 2 \mathrm{~F} 3$ were expressed highly in tumor tissue samples compared to the normal ones with significant difference (Fig. 2A and B). In line with RT-qPCR results, we found that the percentage of p53 positive cells was reduced in tumor samples (Fig. 2C). The data here indicated that $\mathrm{Rb}$ was involved in bladder cancer progression, showing suppressed role in bladder cancer regulation.

Alteration of $R b$ influences apoptosis- and proliferationrelated signal expression in vitro. In this regard, RT-qPCR was used to determine Rb, p53, mTOR and E2F3 levels in bladder cancer cells and normal bladder cells. We found that Rb and p53 expressed highly in T24 cells compared to that in the bladder cancer BIU87 cells (Fig. 3A and B). In contrast, mTOR and E2F3 expression was low in normal T24 bladder cells, which was in line with previous results (Fig. 3C and D). To investigate the mechanisms by which $\mathrm{Rb}$ expression regulates bladder tumor development, we examined the cell proliferation- and apoptosis-related signals affected by $\mathrm{Rb}$ alteration via antibody arrays which analyzed up to 1,000 factors, including chemokines, growth factors, cytokines, as well as other proteins. We cultured BIU87 cells with a control vector or Rb knockdown in serum-deprived media for $48 \mathrm{~h}$ before harvesting the cell culture supernatant for the following antibody array analysis. As shown in Fig. 3E, increased levels of mTOR, E2F3, cyclin D1, Myc, Bcl-2 and CDK4 and decreased levels of Bax were observed in the conditioned media derived from Rb-knockdown cells compared to the control vector-expressing BIU87 cells. Quantitative RT-PCR analysis also indicated that the mRNA levels of mTOR, E2F3, cyclin D1, Bcl-2, Myc and CDK4 were also significantly upregulated while Bax was downregulated in Rb-knockdown BIU87 cells compared with that in the control 
A

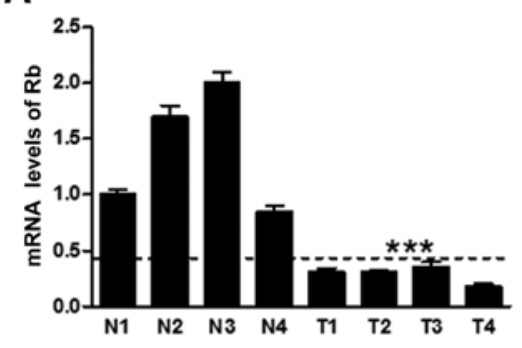

\section{C}

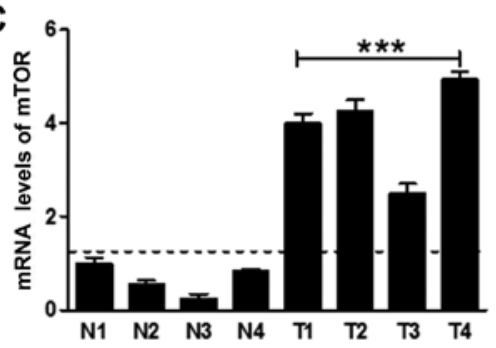

E

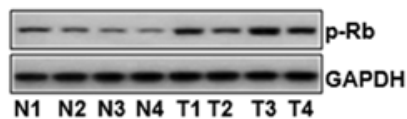

B
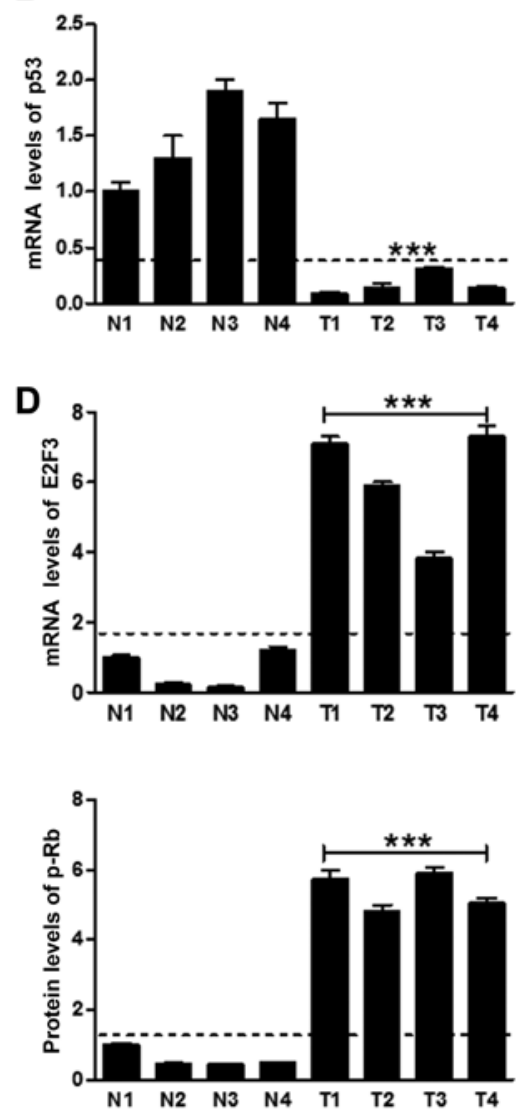

Figure 1. Patients with bladder cancer express low levels of Rb. (A) RT-qPCR was used to explore Rb mRNA levels in the normal tissue samples and bladder tumor tissue samples, respectively. (B) RT-qPCR was used to explore p53 mRNA levels in the normal tissue samples and bladder tumor tissue samples, respectively. (C) RT-qPCR was used to explore mTOR mRNA levels in the normal tissue samples and bladder tumor tissue samples, respectively. (D) RT-qPCR was used to explore E2F3 mRNA levels in the normal tissue samples and bladder tumor tissue samples, respectively. (E) Western blot analysis was performed to investigate $\mathrm{p}$ - $\mathrm{Rb}$ protein levels in the normal tissue samples and bladder tumor tissue samples, respectively. Data are expressed as the mean $\pm \mathrm{SEM}$. ${ }^{* * *} \mathrm{p}<0.001$ versus the normal control.

\section{A}
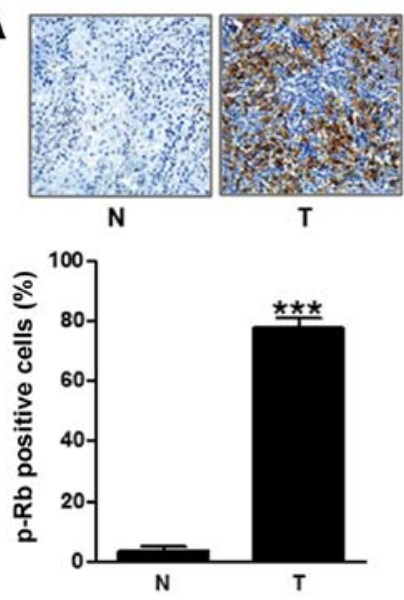

B
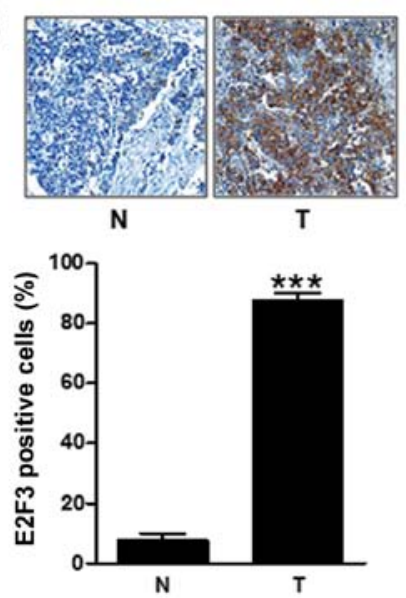

C
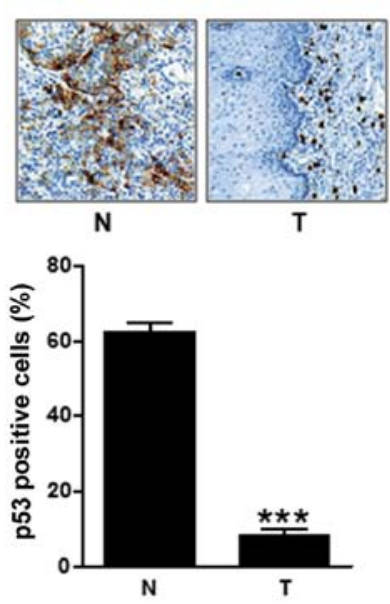

Figure 2. High expression of $\mathrm{p}-\mathrm{Rb}$ is related to bladder cancer development. Immunohistochemical analysis was used to determine (A) p-Rb, (B) E2F3 and (C) 553 levels in the normal tissue samples and bladder tumor tissue samples, respectively. Data are expressed as the mean \pm SEM. ${ }^{* * *}$ p $<0.001$ versus the normal control.

vector-expressing cells (Fig. 3F). Therefore, the findings above suggested that $\mathrm{Rb}$ inhibition in bladder cancer cells promoted expression of mTOR, E2F3, cyclin D1, Bcl-2, Myc and CDK4 companied by Bax downregulation at both the transcriptional and protein levels.
Knockdown of $R b$ accelerates E2F3 and influences the regulatory proteins of proliferation and apoptosis. Previous study indicated that the phosphorylation of $\mathrm{Rb}$ influenced cell proliferation and cell apoptosis through modulating related signaling pathway (22). Therefore, we demonstrated that $\mathrm{Rb}$ 
A

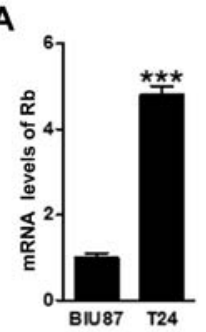

B

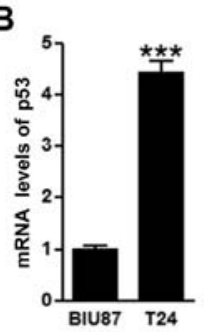

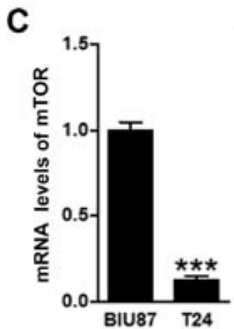

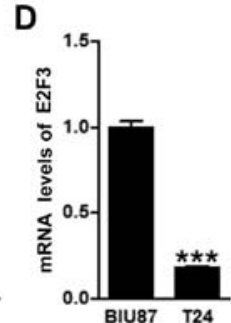

E

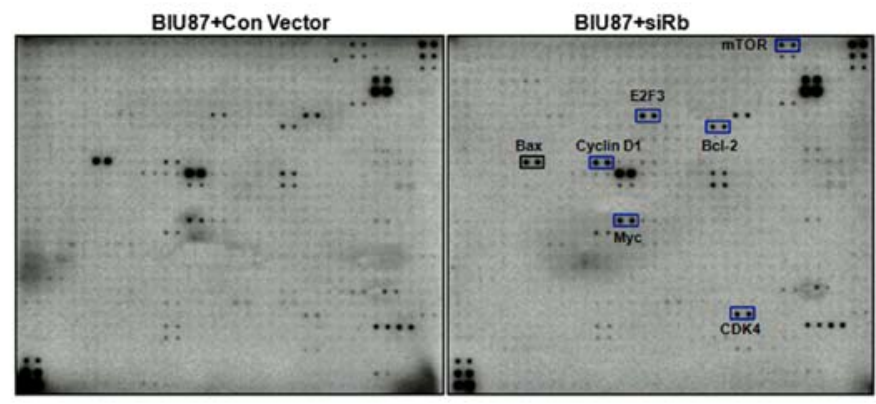

$\mathbf{F}$

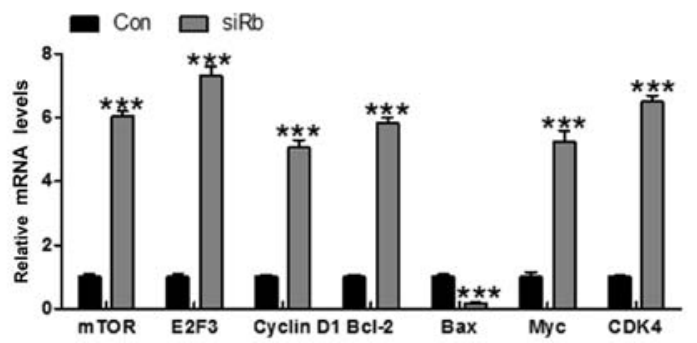

Figure 3. Alteration of Rb influences apoptosis- and proliferation-related signal expression. mRNA levels of (A) Rb, (B) p53, (C) mTOR and (D) E2F3 expressed diffrently in normal and tumor bladder cells of BIU87 and T24, respectively. (E) Antibody array analyses of cell culture supernatants of BIU87 expressing a control vector or silence of Rb. BIU87 cells were cultured in serum-deprived media with $0.1 \%$ FBS for $48 \mathrm{~h}$. Then the cell culture supernatants were collected and labeled with biotin before incubation with array membranes for detection. Upregulated or downregulated proteins are displayed in blue and black colour, respectively. Also, representative images from three independent experiments are exhibited. (F) Quantitative RT-qPCR analysis of mTOR, E2F3, cyclin D1, Bcl-2, Bax, Myc and CDK4 mRNAs in BIU87 cells expressing a control vector and siRb. BIU87 cells were cultured for $48 \mathrm{~h}$ before harvesting for total RNA analysis. Data are expressed as the mean \pm SEM. ${ }^{* * *}$ p $<0.001$ versus the vector control.

A

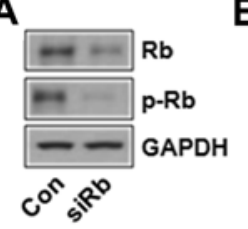

E
C

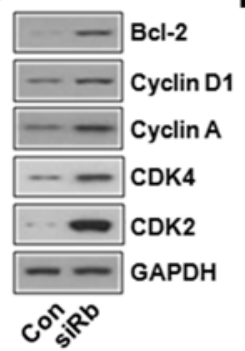

D

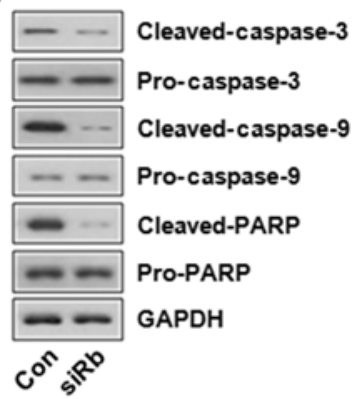

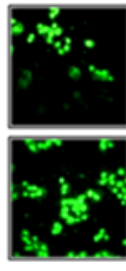

Con

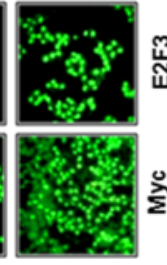

siRb

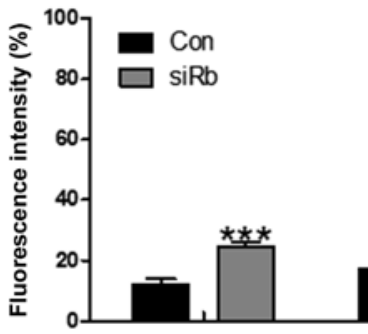

E2F3

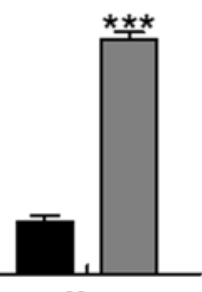

Figure 4. Knockdown of $\mathrm{Rb}$ accelerates $\mathrm{E} 2 \mathrm{~F} 3$ and influences the regulatory proteins of proliferation and apoptosis. (A) Western blot analysis of $\mathrm{Rb}$ and $\mathrm{p}-\mathrm{Rb}$ in BIU87 cells treated with a control vector and siRb. (B) Western blot analysis of E2F3, mTOR and Myc in BIU87 cells treated with a control vector and siRb. (C) Western blot analysis of proliferation-related signals in BIU87 cells treated with a control vector and siRb. (D) Western blot analysis of apoptosis-related signals in BIU87 cells treated with a control vector and siRb. (E) Immunofluorescent analysis of E2F3 and Myc in BIU87 cells treated with a control vector and siRb. Data are expressed as the mean \pm SEM. ${ }^{* * *} \mathrm{p}<0.001$ versus the vector control. 
A
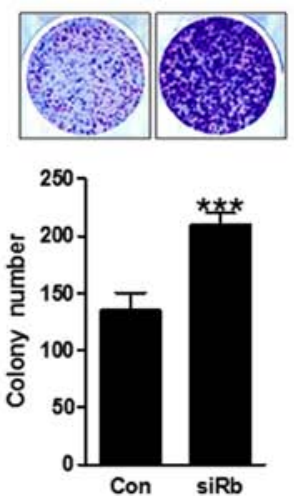

B
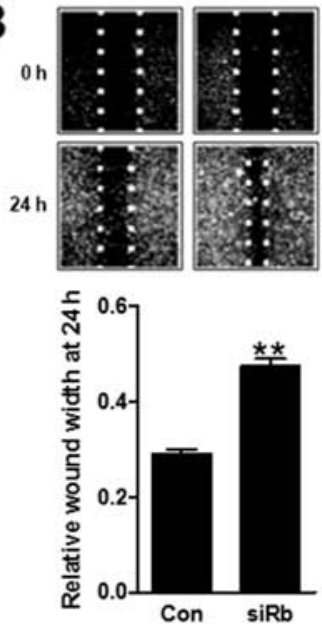

C
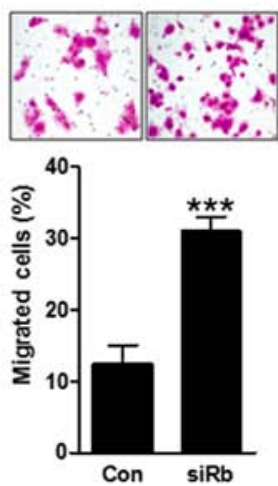
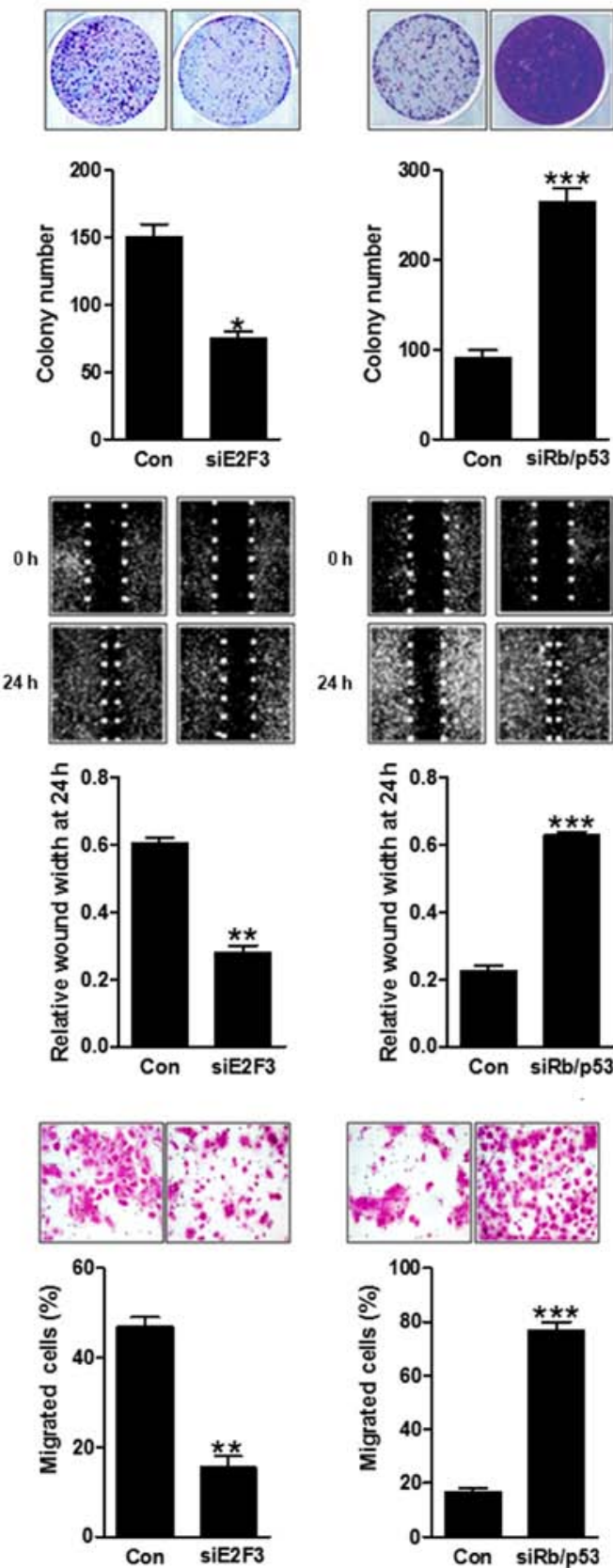
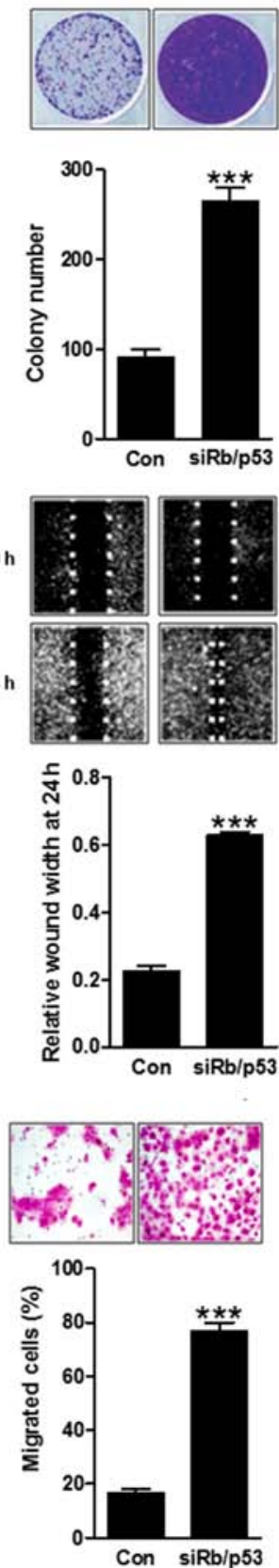

Figure 5. Rb silence promotes bladder cancer cell proliferation and migration. (A) Effect of Rb, E2F3 and p53 expression of BIU87 cells treated with a control vector and siRb or siE2FE and siRb combined with p53 on clonogenic growth of BIU87 cells. (B) The changes in BIU87 cell morphology and spreading after treatment of a control vector and siRb or siE2FE and siRb combined with p53 for $24 \mathrm{~h}$ were studied, and BIU87 cells were photographed via a microscope equipped with digital camera. (C) The migration of BIU87 after treatment of a control vector and siRb or siE2FE and siRb combined with p53, and BIU87 cells were photographed via a microscope equipped with digital camera. Data are expressed as the mean \pm SEM. ${ }^{*}$ p $<0.05,{ }^{* *}$ p $<0.01,{ }^{* * *}$ p $<0.001$ versus the vector control.

phosophorylation induced E2F3 activity through carcinogenic gene induction and apoptosis suppression in different cancer cell lines (23). In order to further determine how Rb performs its role in bladder cancer progression, we knocked down $\mathrm{Rb}$ gene in BIU87 bladder cancer cells. In Fig. 4A, we found that $\mathrm{Rb}$ was successfully silenced with lower expression accompanied with relatively higher level of phosphorylated Rb. Next, E2F3, mTOR and Myc were upregulated significantly in siRb group (Fig. 4B). E2F3, mTOR and Myc are well known to play important roles in contributing to tumor or cancer development (24). Next, the cell proliferation- and apoptosis-related signals were investigated. As shown in Fig. 4C, Bcl-2, a crucial anti-apoptosis factor, was found to be upregulated, inhibiting apoptosis in bladder cancer. Also, cyclin D1, cyclin A, CDK4 and CDK2 were also upregulated in bladder cancer cells with $\mathrm{Rb}$ silenced, suggesting that Rb deficiency was, at least partly, involved in bladder cancer progression through regulating apoptosis and proliferation of cells. Furthermore, cleaved caspase-3, cleaved caspase-9 and cleaved PARP were reduced significantly in BIU87 cells with Rb knockdown, indicating that $\mathrm{Rb}$ was associated with apoptosis, influencing bladder cancer development (Fig. 4D). Additionally, immunofluorescence analysis suggested that E2F3 and Myc were expressed highly in siRb cells compared to the vector control (Fig. 4E). 
A

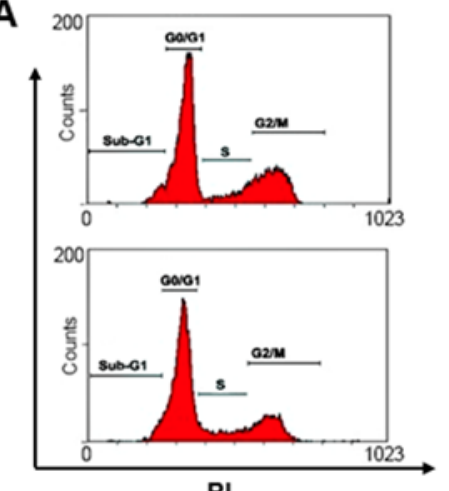

PI

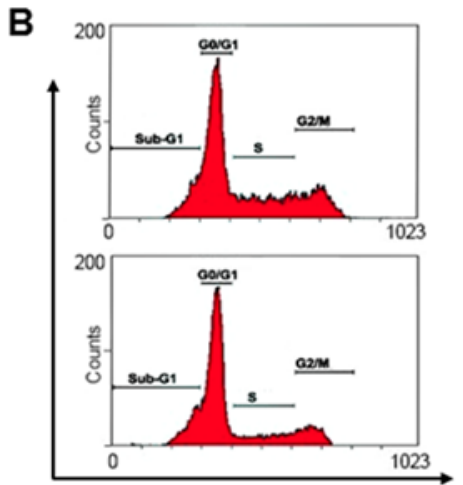

PI

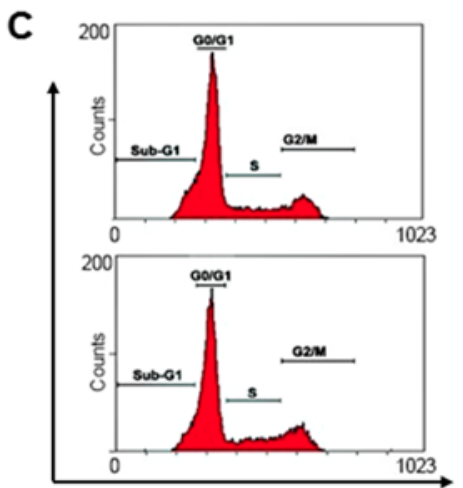

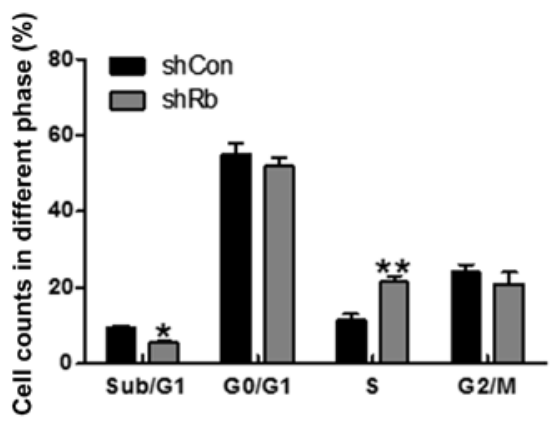
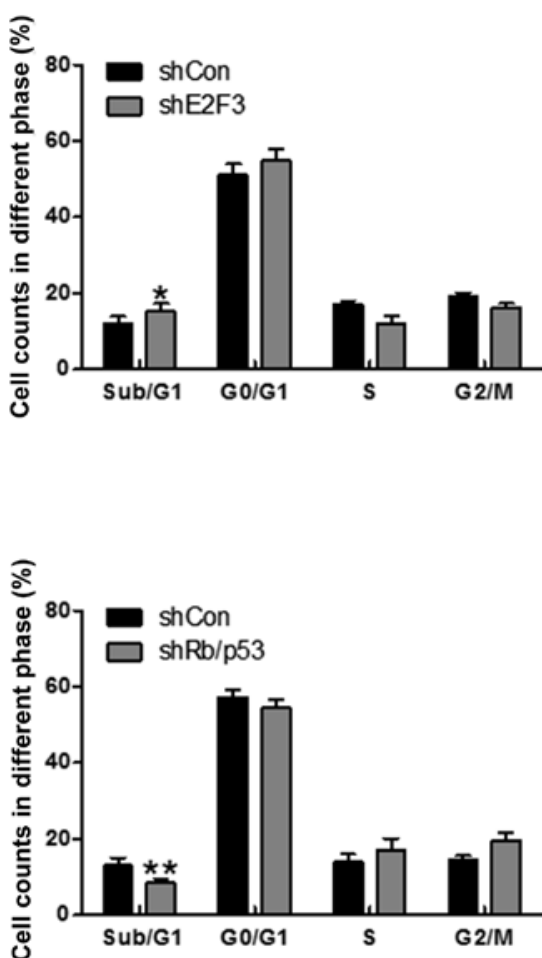

Figure 6. Rb knockdown inhibits apoptosis in BIU87 cancer cells. (A) Cell cycle phase distribution was analysed by flow cytometry in BIU87 cells treated with a control vector and siRb. (B) Cell cycle phase distribution was analysed by flow cytometry in BIU87 cells treated with a control vector and siE2F3. (C) Cell cycle phase distribution was analysed by flow cytometry in BIU87 cells treated with a control vector and siRb combined with sip53. Data are expressed as the mean \pm SEM. ${ }^{*} \mathrm{p}<0.05$, and ${ }^{* *} \mathrm{p}<0.01$ versus the vector control.

Taken together, the data in this part illustrated that $\mathrm{Rb}$ was indeed involved in bladder cancer progression through regulating bladder cancer cell proliferation and apoptosis.

$R b$ silence promotes bladder cancer cell proliferation and migration. In this regard, we investigated the role of $\mathrm{Rb}$ in bladder cancer cell proliferation and migration. As shown in Fig. 5A, the colony formation assay showed that $\mathrm{Rb}$ silence promoted the colony number, while inhibiting E2F3 expression, the colony number was reduced, indicating that E2F3 had a potential role in enhancing bladder cancer cell proliferation. In addition, inhibiting Rb and p53 simultaneously, the colony formation number was higher. Further, the relative wound width at $24 \mathrm{~h}$ indicated that $\mathrm{Rb}$ silence could increase the relative wound width. Also, E2F3 knockdown significantly decreased the relative wound width at $24 \mathrm{~h}$. Similarly, $\mathrm{Rb}$ and p53 silence could further promote the wound width at $24 \mathrm{~h}$ (Fig. 5B). Finally, we investigated the number of migrated cells modulated by Rb, E2F3 and p53. As shown in Fig. 5C, the number of migrated bladder cancer cells was significantly increased in Rb-knockdown cells. In E2F3-silence cells, the number of bladder cancer cells was decreased remarkably. Significnatly, the percentage of migrated cells was increased in $\mathrm{Rb}$ and $\mathrm{p} 53$ knockdown cells concurrently. Together, the data above indicated that $\mathrm{Rb}$ has a potential role in suppressing bladder cancer cell proliferation and migration, which was related to $\mathrm{E} 2 \mathrm{~F} 3$ and $\mathrm{p} 53$ modulation.

Rb knockdown inhibits apoptosis in BIU87 cancer cells. In order to further explore how Rb suppressed BIU87 bladder cancer cell progression, flow cytometry analysis was performed. In Fig. 6A, the counts of bladder cancer cells in 
A
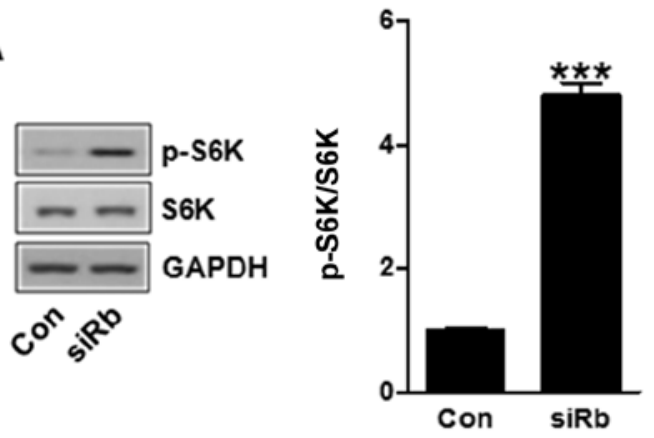

B
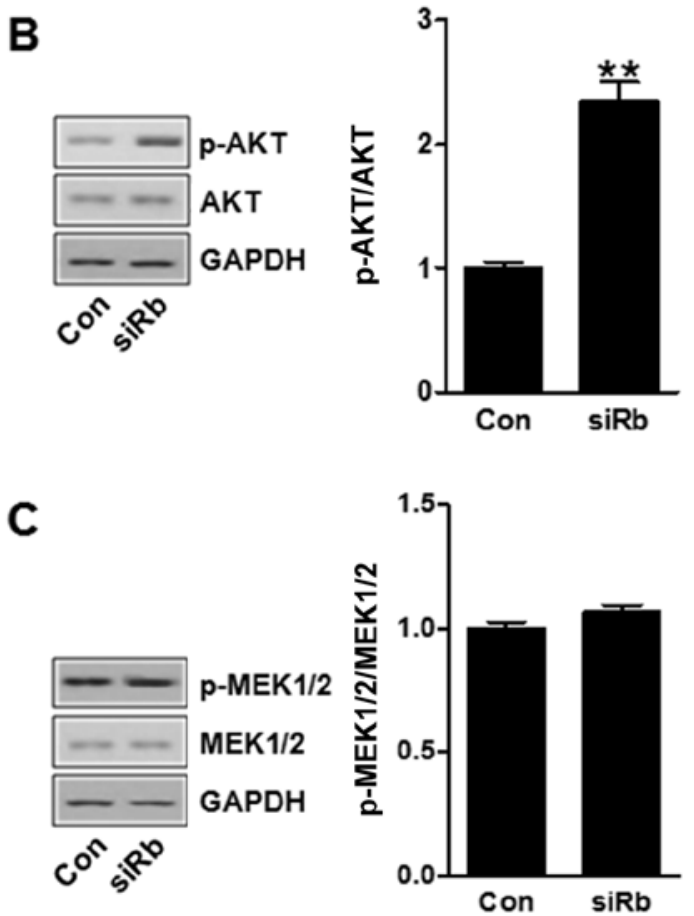

D
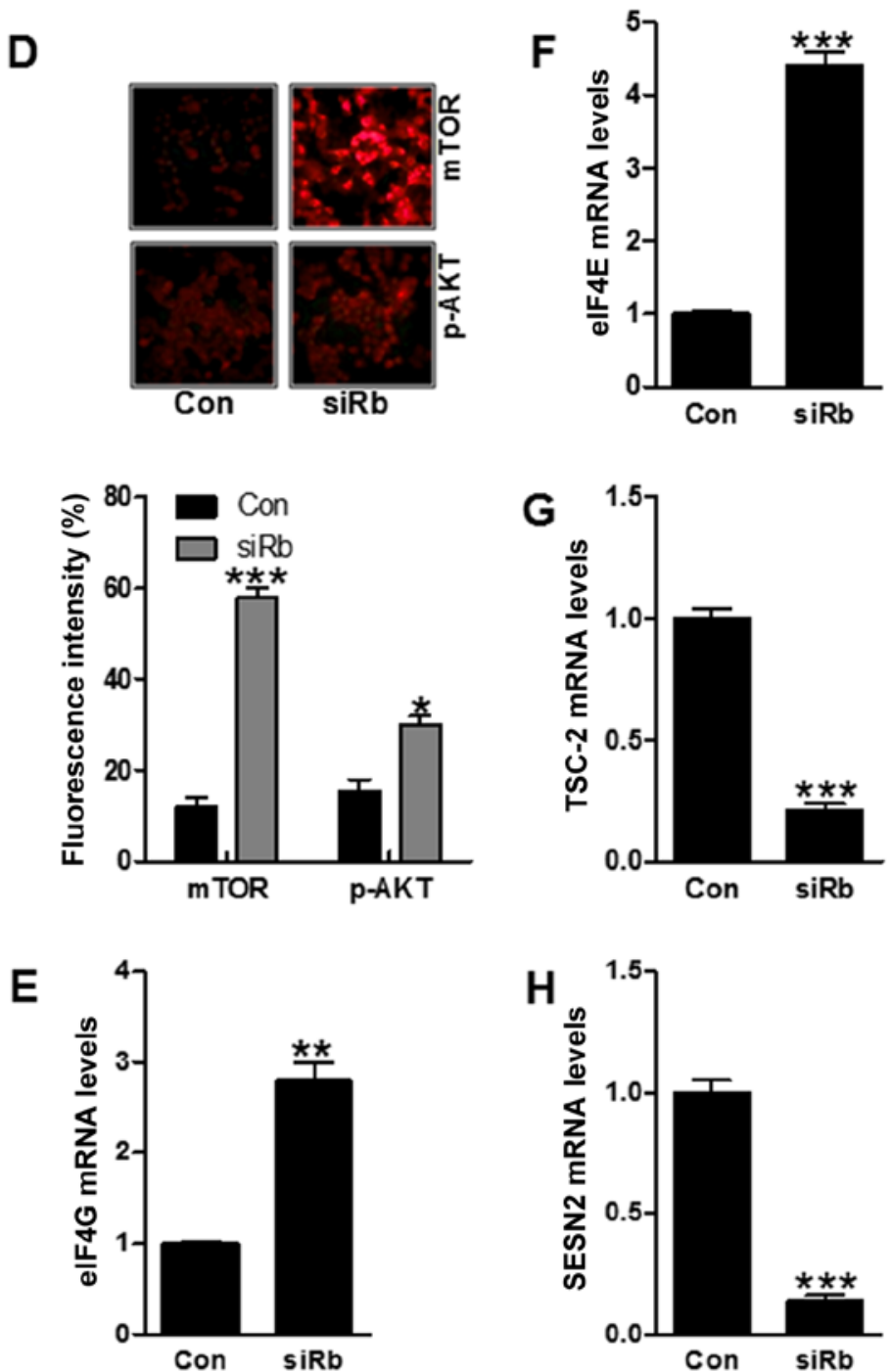
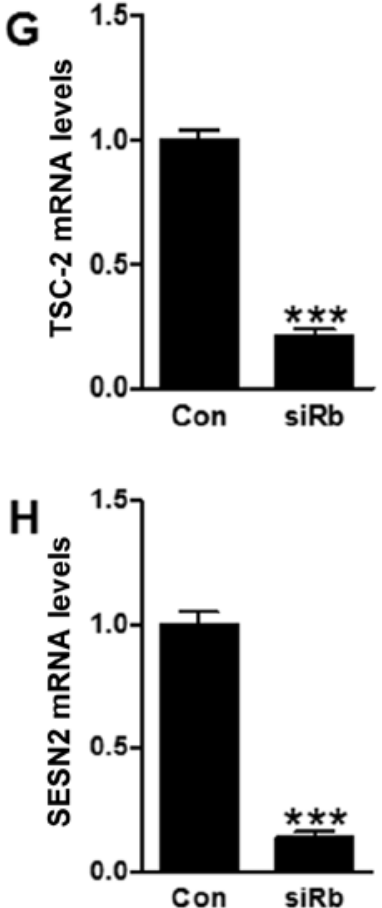

Figure 7. Rb-modulated bladder cancer progression is related to mTOR signaling pathway. (A) p-S6K was significantly increased in siRb as compared with the control with similar total S6K levels. (B) p-AKT was expressed highly in siRb as compared with the control with similar total AKT levels. (C) p-MEK was significantly downregulated in siRb in comparison with the control ones with similar total MEK expressed levels. (D) Immunofluorescent analysis of mTOR and p-AKT in BIU87 cells treated with a control vector and siRb. Quantitative RT-qPCR displayed significantly upregulated expression of eIF4G (E) and eIF4E (F) and downregulated TSC-2 (G) and SESN2 (H) levels compared to the control. Data are expressed as the mean \pm SEM. ${ }^{*}$ p $<0.05,{ }^{* *}$ p $<0.01,{ }^{* * *}$ p $<0.001$ versus the vector control.

sub/G1 phase were lower in the vector control ones in comparison to the $\mathrm{Rb}$-silenced group, further indicating apoptosis was inhibited for $\mathrm{Rb}$ suppression. In addition, E2F3 silence significantly increased the number of BIU87 cells in Sub/G1 phase, inhibiting apoptosis in cells (Fig. 6B). Significantly, silencing $\mathrm{Rb}$ and p53 simultaneosly reduced the number of bladder cancer cells in Sub/G1 phase (Fig. 6C). The results above indicated that $\mathrm{Rb}$ expressed levels were associated with apoptosis development, which could be a potential target for baldder cancer treatment.

$R b$-modulated bladder cancer progression is related to mTOR signaling pathway. S6K, p-AKT and MEK1/2 has been reported to be involved in tumor progression, which are important in mTOR pathway, regulating the cellular process (25). Thus, here we attempted to investigate how $\mathrm{Rb}$ modulated bladder cancer progression via mTOR signaling pathway. Fig. 7A shows that S6K phosphorylated level was higher in Rb-silenced cells, while total S6K was not observed with significant difference. Additionally, phosphorylated AKT levels were also expressed highly in bladder cancer cells after Rb knockdown compared to the vector control (Fig. 7B). In contrast, activated MEK1/2 was found to be reduced after $\mathrm{Rb}$ silence, which was linked with tumor inhibition (Fig. 7C). Moreover, immunofluorescence analysis was used to determine how mTOR and p-AKT changed in siRb bladder cells. As shown in Fig. 7D, mTOR and p-AKT fluorescent intensity was significantly upregulated in BIU87 cells with Rb silence. Additionally, Eif4g and Eif4e were important factors helping to activate mTOR signaling pathway, which was increased by $\mathrm{Rb}$ knockdown (Fig. 7E and F). In contrast, TSC-2 and SESN2, which inhibit mTOR signaling pathway activity, were found to be downregulated with significant difference (Fig. 7G and H). Together, the above results indicated that Rb-regulated bladder cancer progression was closely related to mTOR activation. 
A
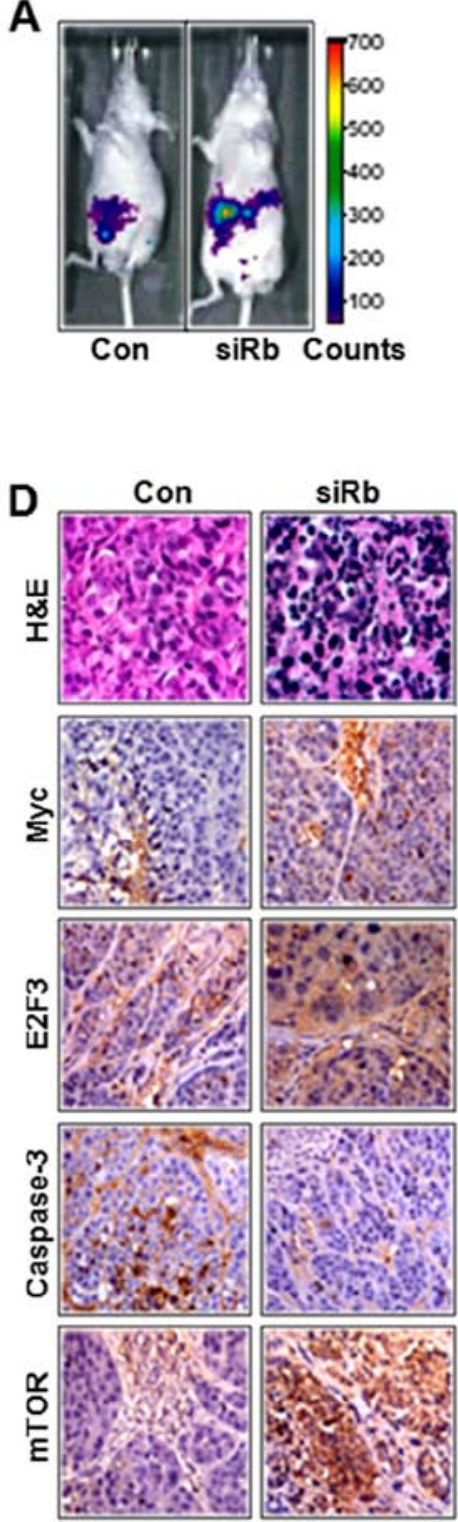

B
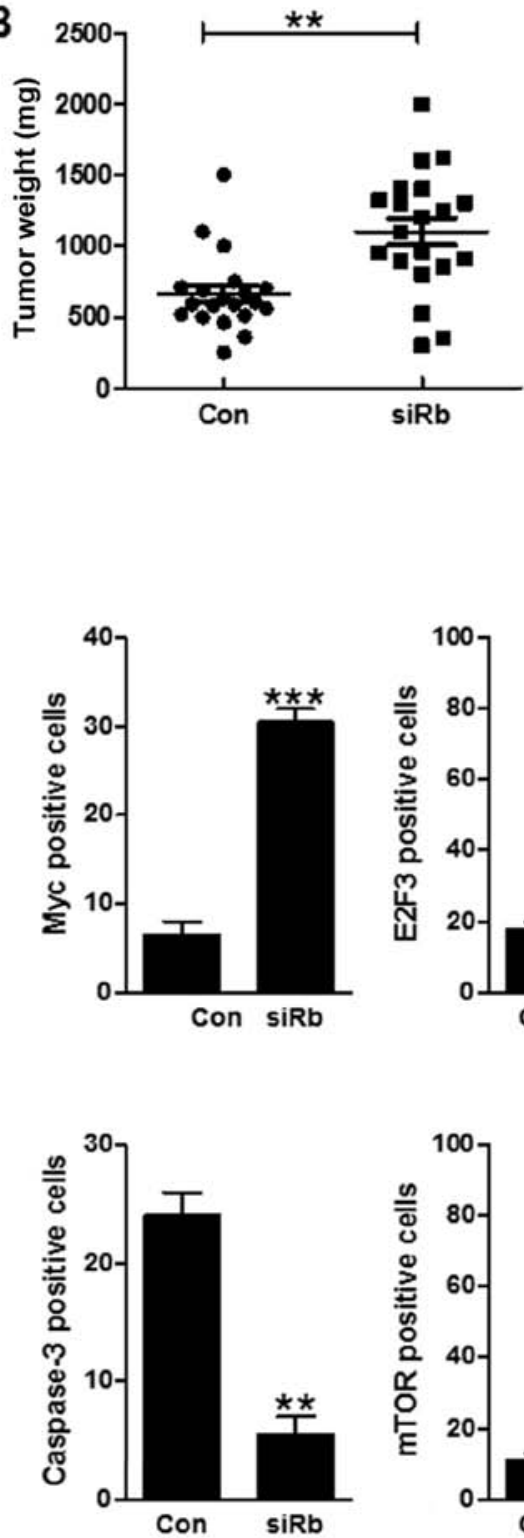

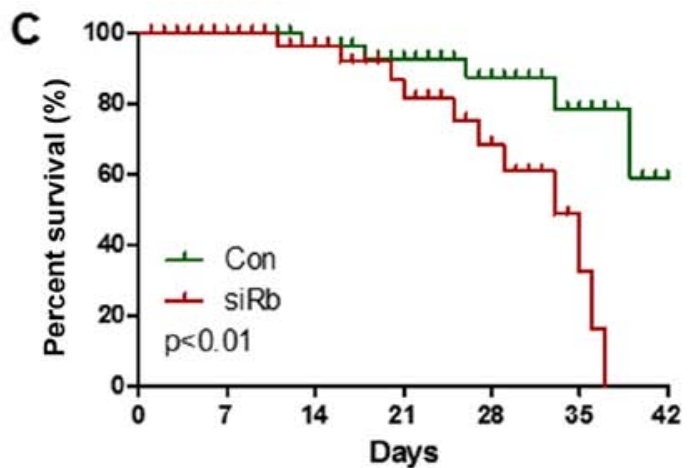

$\mathbf{E}$
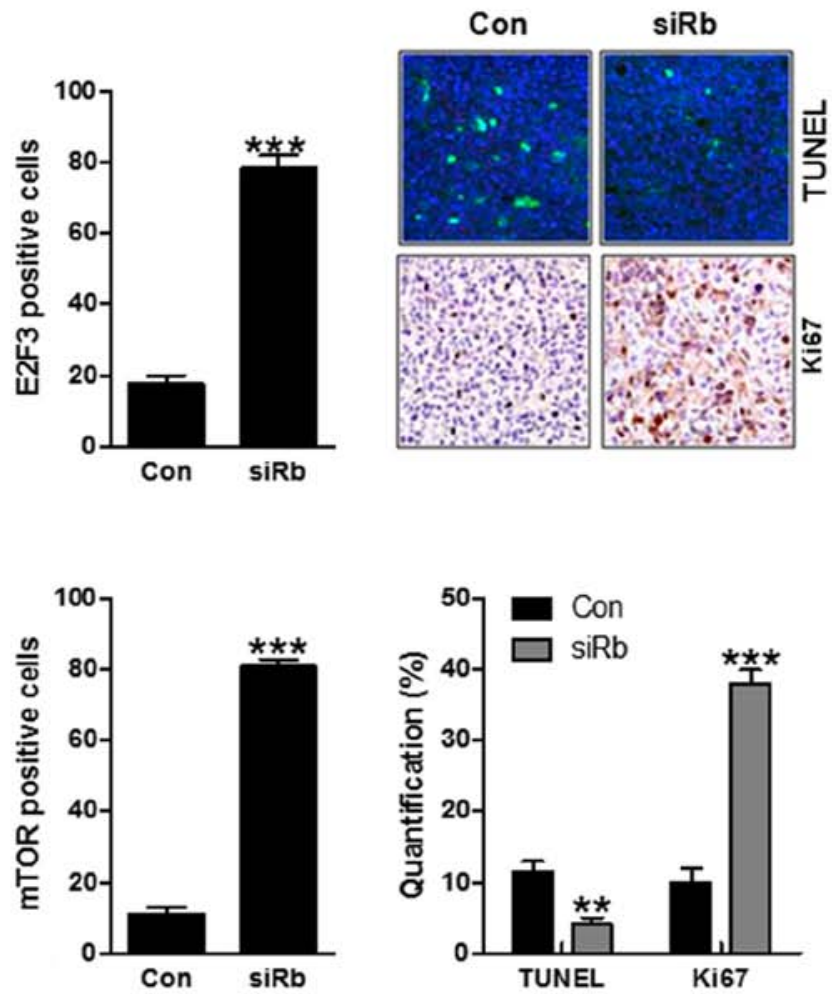

Figure 8. Rb knockdown enhances bladder tumor growth in vivo. (A) Representative images show an increase in luminescence in the lower expression of Rb group compared with the control group. (B) Rb silence upregulated tumor weight in mouse models. (C) Rb knockdown decreased the survival rate of mice with bladder cancer. (D) Immunohistochemical analysis of H\&E, Myc, E2F3, caspase-3 and mTOR in bladder tumor samples of mice. (E) TUNEL and Ki67 analysis were determined in bladder tumor samples in animal models. Data are expressed as the mean $\pm \mathrm{SEM} .{ }^{* *} \mathrm{p}<0.01,{ }^{* * * *} \mathrm{p}<0.001$ versus the vector control.

Rb knockdown enhances bladder tumor growth in vivo. We implanted BIU87+Luc cells expressing inducible vector control siRNA or siRb by intraperitoneal injection into the nude mice. After 42 days, we found that inducible suppression of Rb durably enhanced tumor growth (Fig. 8A). In addition, the tumor weight was also higher in the nude mice injected with $\mathrm{Rb}$-silenced cells compared to the control ones (Fig. 8B). As shown in Fig. 8C, and the results showed that $\mathrm{Rb}$ silence significantly reduced survival rate in mice. Next, $\mathrm{H} \& \mathrm{E}$ staining suggested the morphology of tumor tissue sample in the control group and the siRb group. In addition, immunohistochemical analysis indicated that Myc, E2F3 and mTOR were expressed highly in Rb-silenced tumor tissue samples with significant difference compared to the control, while caspase- 3 was found to be downregulated after $\mathrm{Rb}$ knockdown, which was in line with the above results (Fig. 8D). Further, TUNEL and Ki67 expressed levels were also explored. As shown in Fig. 8E, we found that the TUNEL positive tissue samples were lower after $\mathrm{Rb}$ silence. In contrast, Ki67 expressed highly in Rb-silenced tissue samples. Finally, the cell proliferation- and apoptosis-related signaling pathway was further investigated in vivo. As shown in Fig. 9A, phosphorylated $\mathrm{Rb}$ was expressed highly, a main contributor leading to E2F3 expression. Additionally, Bcl-2, cyclin D1, cyclin A, CDK4 and CDK2 were all upregulated in siRb bladder tumor tissue samples (Fig. 9B). Also, the levels of cleaved caspase-3, and cleaved PARP were signifcantly reduced in Rb-silenced tissue samples, suppressing apoptosis in bladder tumor samples (Fig. 9C). The data above, which was in line with the results in vitro, further suggested that $\mathrm{Rb}$-regulated bladder cancer was related to cell proliferation and apoptosis signaling pathway. 

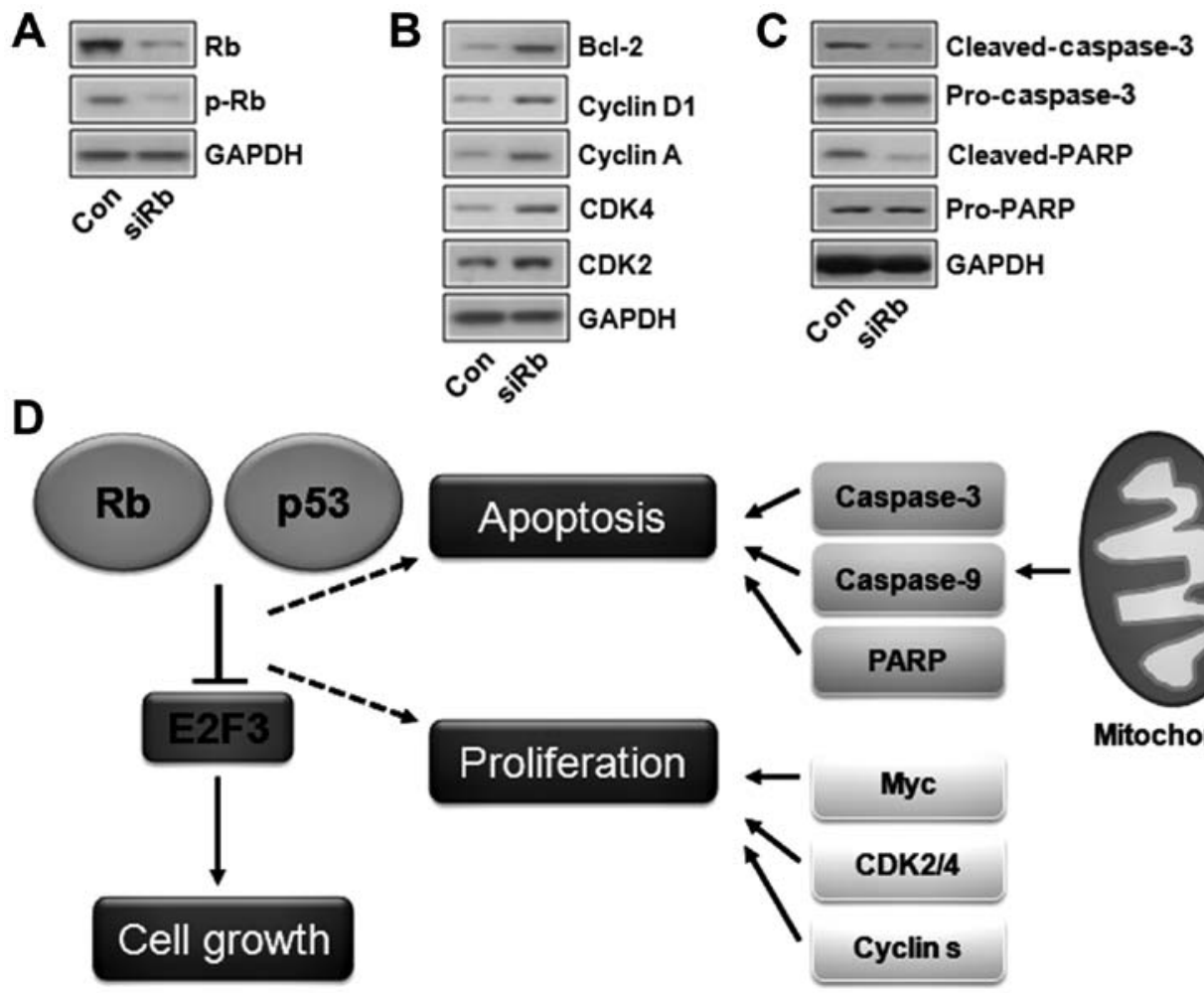

Figure 9. Knockdown of Rb accelerates E2F3 and influenced the regulatory proteins of proliferation and apoptosis in vivo. (A) Western blot analysis of Rb and $\mathrm{p}-\mathrm{Rb}$ in bladder tumor tissues. (B) Western blot analysis of proliferation-related signals in bladder tumor tissues. (C) Western blot analysis of apoptosis-related signals in bladder tumor tissues. (D) The working model of Rb-regulated bladder tumor progression and development. Data are expressed as the mean \pm SEM. ${ }^{*} \mathrm{p}<0.05,{ }^{* *} \mathrm{p}<0.01,{ }^{* * *} \mathrm{p}<0.001$ versus the vector control.

\section{Discussion}

Bladder cancer is one of the most frequent types of cancer among males and a main cause leading to death in the world (26). Initially, although most patients are diagnosed with non-muscle-invasive bladder cancer, a large number of such tumors experience recurrance after therapy and exit muscle invasion eventually $(27,28)$. Recently, researchers have focused on using therapeutic startegies against cancer cells to inhibit cell proliferation and induce apoptosis, representing a programmed self-killing molecular mechanism, which includes extrinsic and intrinsic signaling pathways (29). However, the targeted genes or proteins that impede bladder cancer progression, is still limited. Thus, further research of the molecular mechanisms by which bladder cancer cells migrate and progress are necessary.

Cell cycle dysregulation is known as a hallmark for tumor cells (30). The G1/S checkpoint comprises cyclin D1 and E, $\mathrm{CDK} 2,4$, and 6 , and $\mathrm{Rb}$. Rb plays the role in constraining the $\mathrm{G} 1 / \mathrm{S}$ transition in many mammalian cells. cyclin D-CDK4/6 as well as cyclin E-CDK2 complexes result in the Rb phosphorylation and inactivation cooperatively $(31,32)$. Phosphorylated $\mathrm{Rb}$ regulates E2F3 activation, which is required for the progression into late phase of G1 and S (33). This sequential regulation has additional specificity in modulating alternative cell fates, including differentiation and proliferation, and plays an important role in tumor development and progression (34). The $\mathrm{Rb}$ phosphorylation, resulting in the sequestration of $\mathrm{E} 2 \mathrm{~F} 3$, and then influencing the expression of Myc, which is known as a significant factor, contributing to tumor progression (35). In line with previous reports, our study indicated that $\mathrm{Rb}$ expression was low in bladder tumor tissue samples and bladder cancer cells in vivo and in vitro, respectively. On the contrary, the phosphorylated $\mathrm{Rb}$ was highly expressed in bladder cancer samples and cells, inducing cells cycle arrest in bladder cancer cells, which was dependent on cyclin D1, cyclin A and CDK2/4, as well as E2F3 signaling pathway accompanied by Myc overexpression, contributing to cell proliferation. In addition, E2F3 knockdown ameliorated bladder cancer proliferation and migration, further suggesting that $\mathrm{Rb}$-inhibited bladder cancer progression was at least partly dependent on E2F3 suppression. Tumor suppressor p53 is well known as a critical protein, in apoptosis (36). In our study, we found that combination of Rb and p53 knockdown cound aggravate bladder cancer cell proliferation and apoptosis, suggesting that $\mathrm{Rb}$ might interact together with $\mathrm{p} 53$ to modulate baldder cancer progression.

$\mathrm{Bcl}-2$ family proteins function in various roles in the modulation of cell apoptosis and primarily influence the mitochondrial signaling pathway (37). Bcl-2 stabilizes the cell mitochondrial membrane and inhibits the cytochrome $c$ release and other pro-apoptotic factor expression, while Bax enhances apoptosis. Furthermore, the ratio of $\mathrm{Bcl}-2 / \mathrm{Bax}$ is usually considered as a criterion for programmed cell death (38). In addition, p53 has a close relationship with apoptosis (39). Bcl-2 promotor has a p53-negative responding element, which may the reason for $\mathrm{p} 53$-regulated Bcl-2 transrepression (40). In addition, $\mathrm{Rb}$ has been reported to influence caspase-3 
activation, promoting apoptosis in tumor development (41). In our study, we found that $\mathrm{Rb}$ silence increased $\mathrm{Bcl}-2$ expression, while decreased cleaved caspase- 3 and cleaved PARP levels in vitro and in vivo, inhibiting apoptosis in bladder cancer cells. Furthermore, E2F3 knockdown promoted apoptosis, which was in agreement with previous reports (42). Also, Rb silence combined with p53 could further downregulate apoptosis in bladder cancer cells through flow cytometry analysis. Collectively, our data above indicated that $\mathrm{Rb}$ could combine with p53 affect apoptosis in bladder cancer development.

The mammalian target of rapamycin (mTOR) is a serine/ threonine kinase that is ubiquitously expressed in mammalian cells. mTOR is well known to be associated with tumor development in many cancers $(43,44)$. Also, AKT/mTOR signaling pathway was involved in a variety of tumor types (45). Similarly, our study suggested that mTOR was upregulated in Rb silence. Notably, mTOR activation increased eIF4E and eIF4G via RT-qPCR in siRb group, while TSC-2 and SESN2 were downregulated, which were two negative factors for mTOR activation (46). The S6 kinase (S6K) proteins are some of the main downstream effectors of the mTOR and act as key modulators for protein synthesis and cell growth. S6K activation is overexpressed in a variety of human tumors (47). Similarly, in our study, phosphorylated S6K was observed in $\mathrm{Rb}$-silenced bladder cancer cells. However, no significant difference of MEK1/2 and phosphorylated MEK1/2 was determined, suggeting that $\mathrm{Rb}$-regulated bladder cancer progression was not dependent on MEK1/2 alteration.

Taken together, our data reveal that $\mathrm{Rb}$ functions as a potent tumor suppressor in bladder cancer. Patients with bladder tumor face a clinical prognosis with lower $\mathrm{Rb}$, contributing to cell proliferation and apoptosis inhibiting through E2F3, p53 and mTOR modulation (Fig. 9D). It is essential that we carry out reasearch to understand the pathways through which $\mathrm{Rb}$ and other tumor-suppressing genes control the process of tumor initiation and metastatic progression.

\section{Acknowledgements}

This study was supported by Natural Science Foundation of China (31272391).

\section{References}

1. Zhou J, Li J, Wang Z, Yin C and Zhang W: Metadherin is a novel prognostic marker for bladder cancer progression and overall patient survival. Asia Pac J Clin Oncol 8: e42-e48, 2012.

2. Jemal A, Siegel R, Xu J and Ward E: Cancer statistics, 2010. CA Cancer J Clin 60: 277-300, 2010

3. Huang P, Chen J, Wang L, Na Y, Kaku H, Ueki H, Sasaki K, Yamaguchi K, Zhang K, Saika T, et al: Implications of transcriptional factor, OCT-4, in human bladder malignancy and tumor recurrence. Med Oncol 29: 829-834, 2012.

4. Denzinger S, Mohren K, Knuechel R, Wild PJ, Burger M, Wieland WF, Hartmann A and Stoehr R: Improved clonality analysis of multifocal bladder tumors by combination of histopathologic organ mapping, loss of heterozygosity, fluorescence in situ hybridization, and p53 analyses. Hum Pathol 37: 143-151, 2006

5. Marr BP, Hung C, Gobin YP, Dunkel IJ, Brodie SE and Abramson DH: Success of intra-arterial chemotherapy (chemosurgery) for retinoblastoma: Effect of orbitovascular anatomy. Arch Ophthalmol 130: 180-185, 2012.

6. Ghassemi $\mathrm{F}$ and Shields CL: Intravitreal melphalan for refractory or recurrent vitreous seeding from retinoblastoma. Arch Ophthalmol 130: 1268-1271, 2012.
7. Munier FL, Gaillard M-C, Balmer A, Soliman S, Podilsky G, Moulin AP and Beck-Popovic M: Intravitreal chemotherapy for vitreous disease in retinoblastoma revisited: From prohibition to conditional indications. Br J Ophthalmol 96: 1078-1083, 2012.

8. Zhuang Y and Miskimins WK: Cell cycle arrest in metformin treated breast cancer cells involves activation of AMPK, downregulation of cyclin D1, and requires $\mathrm{p} 27^{\mathrm{Kipl}}$ or $\mathrm{p} 21^{\mathrm{Cip} 1}$. J Mol Signal 3: 18, 2008.

9. Liu B, Fan Z, Edgerton SM, Deng XS, Alimova IN, Lind SE and Thor AD: Metformin induces unique biological and molecular responses in triple negative breast cancer cells. Cell Cycle 8: 2031-2040, 2009.

10. Cooper CS, Nicholson AG, Foster C, Dodson A, Edwards S, Fletcher A, Roe T, Clark J, Joshi A, Norman A, et al: Nuclear overexpression of the E2F3 transcription factor in human lung cancer. Lung Cancer 54: 155-162, 2006.

11. Chen YC, Xu L, Guo YL, Su HJ, Smith TJ, Ryan LM, Lee MS and Christiani DC: Polymorphisms in GSTT1 and p53 and urinary transitional cell carcinoma in south-western Taiwan: A preliminary study. Biomarkers 9: 386-394, 2004.

12. Lin HY, Huang CH, Wu WJ, Chou YH, Fan PL and Lung FW: Mutation of the p53 tumor suppressor gene in transitional cell carcinoma of the urinary tract in Taiwan. Kaohsiung $\mathbf{J}$ Med Sci 21: 57-64, 2005.

13. Wu X, Cai ZD, Lou LM and Zhu YB: Expressions of p53, c-MYC, BCL-2 and apoptotic index in human osteosarcoma and their correlations with prognosis of patients. Cancer Epidemiol 36: 212-216, 2012

14. Mojtahedi Z, Hashemi SB, Khademi B, Karimi M, Haghshenas MR, Fattahi MJ and Ghaderi A: p53 codon 72 polymorphism association with head and neck squamous cell carcinoma. Braz J Otorhinolaryngol 76: 316-320, 2010.

15. Sartor M, Steingrimsdottir H, Elamin F, Gäken J, Warnakulasuriya S, Partridge M, Thakker N, Johnson NW and Tavassoli M: Role of p16/MTS1, cyclin D1 and RB in primary oral cancer and oral cancer cell lines. Br J Cancer 80: 79-86, 1999.

16. Tanaka N, Ogi K, Odajima T, Dehari H, Yamada S, Sonoda T and Kohama G: pRb2/p130 protein expression is correlated with clinicopathologic findings in patients with oral squamous cell carcinoma. Cancer 92: 2117-2125, 2001.

17. Zhou HX, Li XY, Li FY, Liu C, Liang ZP, Liu S, Zhang B, Wang TY, Chu TC, Lu L, et al: Targeting RPTPo with lentiviral shRNA promotes neurites outgrowth of cortical neurons and improves functional recovery in a rat spinal cord contusion model. Brain Res 1586: 46-63, 2014.

18. Shields CL, Shelil A, Cater J, Meadows AT and Shields JA: Development of new retinoblastomas after 6 cycles of chemoreduction for retinoblastoma in 162 eyes of 106 consecutive patients. Arch Ophthalmol 121: 1571-1576, 2003.

19. Ferrari S,Bertoni F,Zanella L, SetolaE, Bacchini P, Alberghini M, Versari M and Bacci G: Evaluation of P-glycoprotein, HER-2/ ErbB-2, p53, and Bcl-2 in primary tumor and metachronous lung metastases in patients with high-grade osteosarcoma. Cancer 100: 1936-1942, 2004

20. Sarbassov DD, Ali SM and Sabatini DM: Growing roles for the mTOR pathway. Curr Opin Cell Biol 17: 596-603, 2005.

21. Foster CS, Falconer A, Dodson AR, Norman AR, Dennis N, Fletcher A, Southgate C, Dowe A, Dearnaley D, Jhavar S, et al: Transcription factor E2F3 overexpressed in prostate cancer independently predicts clinical outcome. Oncogene 23: 5871-5879, 2004.

22. Ziebold U, Reza T, Caron A and Lees JA: E2F3 contributes both to the inappropriate proliferation and to the apoptosis arising in $\mathrm{Rb}$ mutant embryos. Genes Dev 15: 386-391, 2001.

23. McClellan KA, Ruzhynsky VA, Douda DN, Vanderluit JL, Ferguson KL, Chen D, Bremner R, Park DS, Leone G and Slack RS: Unique requirement for $\mathrm{Rb} / \mathrm{E} 2 \mathrm{~F} 3$ in neuronal migration: Evidence for cell cycle-independent functions. Mol Cell Biol 27: 4825-4843, 2007.

24. Oeggerli M, Tomovska S, Schraml P, Calvano-Forte D, Schafroth S, Simon R, Gasser T, Mihatsch MJ and Sauter G: E2F3 amplification and overexpression is associated with invasive tumor growth and rapid tumor cell proliferation in urinary bladder cancer. Oncogene 23: 5616-5623, 2004.

25. Bärlund M, Forozan F, Kononen J, Bubendorf L, Chen Y, Bittner ML, Torhorst J, Haas P, Bucher C, Sauter G, et al: Detecting activation of ribosomal protein S6 kinase by complementary DNA and tissue microarray analysis. J Natl Cancer Inst 92: 1252-1259, 2000. 
26. Urquidi V, Kim J, Chang M, Dai Y, Rosser CJ and Goodison S: CCL18 in a multiplex urine-based assay for the detection of bladder cancer. PLoS One 7: e37797, 2012.

27. Jemal A, Bray F, Center MM, Ferlay J, Ward E and Forman D: Global cancer statistics. CA Cancer J Clin 61: 69-90, 2011.

28. Eruslanov E, Neuberger M, Daurkin I, Perrin GQ, Algood C, Dahm P, Rosser C, Vieweg J, Gilbert SM and Kusmartsev S: Circulating and tumor-infiltrating myeloid cell subsets in patients with bladder cancer. Int J Cancer 130: 1109-1119, 2012.

29. Mitra AP, Hansel DE and Cote RJ: Prognostic value of cellcycle regulation biomarkers in bladder cancer. Semin Oncol 39: 524-533, 2012.

30. Kato K, Gong J, Iwama H, Kitanaka A, Tani J, Miyoshi H, Nomura K, Mimura S, Kobayashi M, Aritomo Y, et al: The antidiabetic drug metformin inhibits gastric cancer cell proliferation in vitro and in vivo. Mol Cancer Ther 11: 549-560, 2012.

31. Schefler AC, Cicciarelli N, Feuer W, Toledano S and Murray TG: Macular retinoblastoma: Evaluation of tumor control, local complications, and visual outcomes for eyes treated with chemotherapy and repetitive foveal laser ablation. Ophthalmology 114: 162-169, 2007.

32. Shields CL: Forget-me-nots in the care of children with retinoblastoma. Semin Ophthalmol 23: 324-334, 2008.

33. Shields CL, Palamar M, Sharma P, Ramasubramanian A, Leahey A, Meadows AT and Shields JA: Retinoblastoma regression patterns following chemoreduction and adjuvant therapy in 557 tumors. Arch Ophthalmol 127: 282-290, 2009.

34. Yang L, Meng Y, Bao C, Liu W, Ma C, Li A, Xuan Z, Shan G and Jia Y: Robustness and backbone motif of a cancer network regulated by miR-17-92 cluster during the $\mathrm{G}_{1} / \mathrm{S}$ transition. PLoS One 8: e57009, 2013.

35. Humbert PO, Verona R, Trimarchi JM, Rogers C, Dandapani S and Lees JA: E2f3 is critical for normal cellular proliferation. Genes Dev 14: 690-703, 2000.

36. Buzzai M, Jones RG, Amaravadi RK, Lum JJ, DeBerardinis RJ, Zhao F, Viollet B and Thompson CB: Systemic treatment with the antidiabetic drug metformin selectively impairs p53-deficient tumor cell growth. Cancer Res 67: 6745-6752, 2007.

37. Callagy GM, Pharoah PD, Pinder SE, Hsu FD, Nielsen TO, Ragaz J, Ellis IO, Huntsman D and Caldas C: Bcl-2 is a prognostic marker in breast cancer independently of the Nottingham Prognostic Index. Clin Cancer Res 12: 2468-2475, 2006.
38. Dawson SJ, Makretsov N, Blows FM, Driver KE, Provenzano E, Le Quesne J, Baglietto L, Severi G, Giles GG, McLean CA, et al: BCL2 in breast cancer: A favourable prognostic marker across molecular subtypes and independent of adjuvant therapy received. Br J Cancer 103: 668-675, 2010

39. Tse C, Shoemaker AR, Adickes J, Anderson MG, Chen J, Jin S, Johnson EF, Marsh KC, Mitten MJ, Nimmer P, et al: ABT-263: A potent and orally bioavailable Bcl-2 family inhibitor. Cancer Res 68: 3421-3428, 2008

40. Nedelcu T, Kubista B, Koller A, Sulzbacher I, Mosberger I, Arrich F, Trieb K, Kotz R and Toma CD: Livin and Bcl-2 expression in high-grade osteosarcoma. J Cancer Res Clin Oncol 134: 237-244, 2008

41. Wang ZX, Yang JS, Pan X, Wang JR, Li J, Yin YM and De W: Functional and biological analysis of Bcl-xL expression in human osteosarcoma. Bone 47: 445-454, 2010.

42. Wensveen FM, Alves NL, Derks IA, Reedquist KA and Eldering E: Apoptosis induced by overall metabolic stress converges on the Bcl-2 family proteins Noxa and Mcl-1. Apoptosis 16: 708-721, 2011.

43. Petroulakis E, Mamane Y, Le Bacquer O, Shahbazian D and Sonenberg N: mTOR signaling: Implications for cancer and anticancer therapy. Br J Cancer 94: 195-199, 2006.

44. Murayama T, Inokuchi M, Takagi Y, Yamada H, Kojima K, Kumagai J, Kawano $\mathrm{T}$ and Sugihara K: Relation between outcomes and localisation of p-mTOR expression in gastric cancer. Br J Cancer 100: 782-788, 2009.

45. Fajas L, Landsberg RL, Huss-Garcia Y, Sardet C, Lees JA and Auwerx J: E2Fs regulate adipocyte differentiation. Dev Cell 3: 39-49, 2002.

46. Liu J, Li M, Song B, Jia C, Zhang L, Bai X and Hu W: Metformin inhibits renal cell carcinoma in vitro and in vivo xenograft. Urol Oncol 31: 264-270, 2013.

47. Shaw RJ, Lamia KA, Vasquez D, Koo SH, Bardeesy N, Depinho RA, Montminy M and Cantley LC: The kinase LKB1 mediates glucose homeostasis in liver and therapeutic effects of metformin. Science 310: 1642-1646, 2005. 